\title{
Are dental care providers in Saudi Arabia prepared to treat patients with special needs?
}

This article was published in the following Dove Press journal:

Journal of Multidisciplinary Healthcare

\author{
Arwa Alumran \\ Luloah Almulhim \\ Bainah Almolhim \\ Shouq Bakodah \\ Hessa Aldossary \\ Saja A Alrayes
}

Health Information Management and Technology Department, College of Public Health, Imam Abdulrahman bin Faisal University, Alkhobar, Saudi Arabia
Background: Equity in services accessibility is one of the major components of good quality healthcare. However, patients with special needs have limited access to dental care services, which could be due to the lack of training and experience of the dental care providers that might effect on their preparedness and willingness when it comes to caring for the patients with special needs.

Objectives: The main objective of this study is to determine the factors influencing the preparedness and willingness of dental care providers at different Saudi Arabian universities to provide treatment to patients with special needs.

Methods: A Cross-sectional study design targeting all dental care providers such as interns, residents, specialists, consultants, dental nurses and students from universities around Saudi Arabia. Two scales were adapted to determine the dental care providers' perceived preparedness and willingness to treat patients with special needs.

Results: A total of 243 participants from dental colleges around Saudi universities were included in the study. Males appeared to be more prepared and willing to treat patients with special needs compared to females. Dental care providers from King Saud University perceived more preparedness compared to other universities in the study. While graduates from King Abdulaziz University exhibit more preparedness to treat patients with special needs compared to graduates from other universities in the study. Also, dental care providers who have treated a patient with special needs perceived more preparedness to treat them again.

Conclusion: When a dental care provider have treated a patient with special needs or just dealt with them in a daily life, this experience procured high preparedness score, however, did not influence on their willingness score in the treatment of these individuals. Good dental education programs are important to provide equity of dental care services to all parts of the community equally.

Keywords: autism spectrum disorder, dental care, oral health, dental education, quality of healthcare, social determinants of health

Dental care is one of the nine elements of primary health care, according to the World Health Organization. Dental health-promotion activities include educating patients on the importance of oral health, routine dental checkups, and the treatment of oral diseases and conditions. ${ }^{1}$ Oral health is paramount to an individual's well-being. However, patients with special needs are likely to experience poor oral health and to have limited access to dental care. This has led to an increase in oral health diseases among patients with special needs; if not managed properly, these diseases are costly to governments and patients. Researchers have indicated that individuals with special health care needs are at elevated risk of developing dental complications, as compared to other individuals. ${ }^{2-4}$ Moreover, the predoctoral curricula for treating patients with special needs are
Correspondence: Arwa Alumran Health Information Management and Technology Department, College of

Public Health, Imam Abdulrahman bin Faisal University, P.O.Box 40I40,

Alkhobar 31952, Saudi Arabia

Tel +9660506845783

Email aalumran@iau.edu.sa 
inadequate. ${ }^{5}$ According to Mustafa et al, ${ }^{5}$ dental studentsfuture oral health providers-lack adequate exposure to patients with special needs. This lack of training and experience also affects their preparedness and willingness related to care for people with special needs. ${ }^{6-8}$ In Saudi Arabia, only pediatric dentists can treat patients with special needs.

We expect that providing proper training to dental care providers will ensure that they are prepared and willing to treat patients with special needs, which in turn will increase the quality of health care that they provide to those patients.

The main research goal is to determine whether the dental caregivers at various Saudi universities are wellequipped to provide treatments to patients with special needs. Furthermore, the study is meant to assess the dental care providers' perceptions on issues pertaining to education and to the treatments that affect access to dental care for patients with special needs.

In the literature, the data are limited regarding the factors that affect access to dental care services for patients with special needs. Two of these factors are dental care providers' preparedness and willingness to treat such patients. In this study, we examine how these factors affect dental care providers. The first main objective of this research is to determine the differences in perceived willingness and preparedness to treat patients with special needs among dental care providers at various Saudi Arabian universities. The second main objective is to assess the factors that affect these perceptions. We conducted this study to identify differences among dental care providers from Imam Abdulrahman bin Faisal University (IAU), King Saud University (KSU), King Abdul-Aziz University (KAU), and other institutions. This study's findings would provide insights into the best ways to improve dental care providers' perceived preparedness to treat patients with special needs.

\section{Methodology}

This study's design is quantitative and cross-sectional. We were interested in determining which factors influence dental care providers' preparedness and willingness to treat patients with special needs, as these factors may limit such patients' access to dental care. The following are some definitions of the key terms used in this study. First, the term patients with special needs includes individuals who are disabled due to physical limitations (congenital, traumatic, or physiological), medical complications (systemic, acquired, or hereditary), developmental problems (congenital or acquired), or cognitive impairments (mental, sensory, emotional, or behavioral. $^{9,10}$ Second, the term special needs dentistry refers to the delivery of oral health care to persons with special needs or disabilities. ${ }^{11}$ Third, the term oral health refers to the state of being free from all mouth and facial conditions that could result in pain or discomfort or that could reduce psychosocial well-being. ${ }^{12}$

The study was undertaken at Imam Abdulrahman bin Faisal University (IAU) in Dammam, King Saud University (KSU) in Riyadh, King Abdul-Aziz University (KAU) in Jeddah, and at other institutions (Najran University, King Khalid University, Prince Sultan Military College of Health Sciences, and AlFarabi Dental College). To some extent, All the programs have similar study plan and courses.

This study includes all dental care providers: interns, residents, specialists, consultants, dental nurses, and dental students. The total population at IAU comprises 691 (including dentists, dental students, and dental assistants). Assuming that all the other universities have the same populations, the study population would be 2073 (270 dentists, 1,410 dental students 393 dental assistants); the required sample size for a $95 \%$ confidence interval is thus 235 participants, leading to a 3.2 confidence level and a population proportion of $50 \%$. Any dental care provider who deals directly with patients is included in this study, and any who do not, such as IT employees and housekeepers, are excluded.

We conducted a thorough literature review to identify a suitable (valid and reliable) scale for use in this study. ${ }^{13}$ The two chosen scales ${ }^{8,14}$ are the ones with the most applicable questions. We then adapted these scales to the study and considered the face validation and retest reliability of the Alkahtani et al ${ }^{14}$ scale.

Alumran (2018) discussed most of the items from this study's survey, which has five sections: demographics, education, experience, willingness, and perceived preparedness. The survey includes four items in the demographics section, three in the education section, four in the experience section, three in the willingness section, and six in the perceived preparedness section. The answers use a 5-point Likert scale ranging from 0 (strongly disagree) to 4 (strongly agree).

The participants filled out an online questionnaire to provide their data. The online questionnaire was helpful, as it allowed for data collection from various Saudi Arabian universities.

The IAU Institutional Review Board and Research Ethics Committee approved this study, IRB-UGS-2018-03-017. The questionnaire included a consent form, and all participants had to state their agreement to participate in the study. 
The software for this study's data analysis is Statistical Package for the Social Sciences. ${ }^{15}$ We conducted a descriptive analysis using means and standard deviations for continuous variables and frequencies and percentages for categorical variables.

The outcome variables were the preparedness score and the willingness score. Because these outcome variables were continuous and had normal distributions, we used a $t$-test, an Analysis of Variance (ANOVA), and a test of Pearson's correlation coefficient for bivariate analysis. We also conducted a multivariable regression, using Stata Software (StataCorp LP, College Station, TX, USA)

\section{Results}

The participants ( 243 dental care providers from the aforementioned Saudi Arabian universities) responded to the online survey; $20.1 \%$ were from KAU, $27.4 \%$ were from $\mathrm{KSU}, 37.2 \%$ were from IAU, and $15.4 \%$ were from other universities. Regarding gender, 94 respondents $(40.2 \%)$ were male, and $140(59.8 \%)$ were female (Table 1).

Based on our study objectives, the providers preparedness and willingness were measured in relation to many variables: gender, age, nationality, and job title; associated current university, the university they graduated from (undergraduate), and board; and general experience with people who have special needs or developmental disabilities, experience treating such people, and concern related to providing dental treatments to them (Tables $2 \& 3$ ). We measured the bivariate associations using a $t$-test and an ANOVA (Tables 2 \& 3). Furthermore, the correlation between the preparedness and the willingness scores was significant $(r=0.351$, $p<0.001$ ), using Pearson correlation coefficient.

The preparedness score showed significant differences across the universities where the participants worked or studied ( $f=6.098, p=0.001)$. Participants who worked or studied at the Faculty of Dentistry in KSU exhibited higher perceived preparedness than did the participants from the other universities in the study (eg, IAU Dental College in Dammam, and KAU Dental College in Jeddah; Figure 1).

In addition, the preparedness scores varied significantly among the alumni from various universities $(f=2.351$, $p=0.003)$. Graduates of King Abdul-Aziz Dental College had the highest perceived preparedness (Figure 2).

To determine the participants' willingness scores and the factors affecting them, we performed an ANOVA to measure how the universities that the providers worked for or study at $(f=0.263, p=0.954)$ and universities that they graduated from $(f=0.115, p=0.951)$ affected the
Table I Characteristics of study participants

\begin{tabular}{|c|c|}
\hline \multicolumn{2}{|l|}{ Demographic variables } \\
\hline Variable & $\mathbf{N}=234(\%)$ \\
\hline \multicolumn{2}{|l|}{ Gender } \\
\hline Male & $94(40.2 \%)$ \\
\hline Female & $140(59.8 \%)$ \\
\hline \multicolumn{2}{|l|}{ Age } \\
\hline $18-24$ & $152(65 \%)$ \\
\hline $25-34$ & $60(25.6 \%)$ \\
\hline $35-44$ & $166.8 \%)$ \\
\hline $45-54$ & $4(4 \%)$ \\
\hline 55 and over & $2(0.9 \%)$ \\
\hline \multicolumn{2}{|l|}{ Nationality } \\
\hline Saudi & 225 (96.2\%) \\
\hline Non-Saudi & $9(3.8 \%)$ \\
\hline \multicolumn{2}{|l|}{ Job title } \\
\hline Consultant & $18(7.7 \%)$ \\
\hline Dental nurse & $4(1.7 \%)$ \\
\hline Intern & 26 (II.1\%) \\
\hline Resident & $31(13.2 \%)$ \\
\hline Specialist & $14(6 \%)$ \\
\hline Student & $133(56.8 \%)$ \\
\hline Other Title & $8(3.4 \%)$ \\
\hline \multicolumn{2}{|l|}{ Educational information variables } \\
\hline \multicolumn{2}{|l|}{ University you work/study in } \\
\hline King Abdul-Aziz University & $47(20.1 \%)$ \\
\hline King Saud University & $64(27.4 \%)$ \\
\hline Imam Abdulrahman bin Faisal University & $87(37.2 \%)$ \\
\hline Other & $36(15.4 \%)$ \\
\hline \multicolumn{2}{|l|}{ Graduation university (College of Dentistry) } \\
\hline King Abdulaziz University & $15(6.4 \%)$ \\
\hline King Saud University & $33(14.1 \%)$ \\
\hline Imam Abdulrahaman bin Faisal University & $4 \mathrm{I}(\mathrm{I} .5 \%)$ \\
\hline Other & $20(8.5 \%)$ \\
\hline No Applicable & $125(53.4 \%)$ \\
\hline \multicolumn{2}{|l|}{ Certifying Board } \\
\hline Saudi & $106(45.3 \%)$ \\
\hline Other & $128(54.7 \%)$ \\
\hline
\end{tabular}

willingness scores. These factors were not significant and thus did not affect the providers' willingness to treat these patients.

For gender, we used an independent $t$-test analysis to measure preparedness. The result was statistically significant, so the providers' gender affects their preparedness to treat patients with special needs $(t=3.007, p=0.003)$. The male participants were more prepared than the female participants to deliver treatments to patients with special needs (Figure 3). 
Table 2 Bivariate analysis of the preparedness and willingness and study factors (part I)

\begin{tabular}{|c|c|c|c|c|}
\hline \multirow[t]{2}{*}{ Variables } & \multicolumn{2}{|c|}{ Preparedness } & \multicolumn{2}{|l|}{ Willingness } \\
\hline & Mean (SD) & Test & Mean (SD) & Test \\
\hline \multicolumn{5}{|l|}{ Gender } \\
\hline Male & $8.78(3.364)$ & independent t-test $=3.007^{*}$ & $7.20(2.256)$ & $t=2.822 *$ \\
\hline Female & $4.4 I(3.516)$ & & $6.33(2.373)$ & \\
\hline \multicolumn{5}{|l|}{ Age (years) } \\
\hline $18-24$ & $7.75(3.465)$ & $f=0.789$ & $6.65(2.313)$ & $f=0.134$ \\
\hline $25-34$ & $8.12(3.355)$ & & $6.72(2.498)$ & \\
\hline $35-44$ & 9.25 (3.907) & & $6.69(2.600)$ & \\
\hline $45-54$ & $8.75(5.965)$ & & $7.50(2.082)$ & \\
\hline 55 and over & $7.50(4.950)$ & & $6.50(2.121)$ & \\
\hline \multicolumn{5}{|l|}{ Nationality } \\
\hline Saudi & $7.96(3.536)$ & independent $t$-test $=0.141$ & $6.69(2.381)$ & $t=0.305$ \\
\hline Non-Saudi & $8.11(3.060)$ & & $6.44(1.878)$ & \\
\hline \multicolumn{5}{|l|}{ Job title } \\
\hline Consultant & $8.11(4.849)$ & $f=1.633$ & $7.11(2.968)$ & $f=0.263$ \\
\hline Dental nurse & $7.75(1.708)$ & & $6.00(0.00)$ & \\
\hline Intern & 7.54 (3.547) & & $6.92(2.529)$ & \\
\hline Resident & $9.13(3.594)$ & & $6.58(2.630)$ & \\
\hline Specialist & $9.00(3.138)$ & & $6.93(2.303)$ & \\
\hline Student & $7.53(3.360)$ & & $6.60(2.230)$ & \\
\hline Other title & $9.88(2.031)$ & & $6.63(2.560)$ & \\
\hline \multicolumn{5}{|c|}{ University do you work/study in } \\
\hline KAU & $7.60(3.905)$ & $f=6.098 * *$ & $6.79(2.349)$ & $f=1.053$ \\
\hline KSU & $8.94(3.318)^{*}$ & & $6.89(2.589)$ & \\
\hline IAU & $6.94(3.160)^{*}$ & & $6.34(2.364)$ & \\
\hline Other & $9.14(3.432)^{*}$ & & $7(1.882)$ & \\
\hline \multicolumn{5}{|c|}{ Graduation college } \\
\hline KAU & $10.00(4.07 \mid)$ & $f=2.61 I^{*}$ & $6.87(2.503)$ & $f=0.091$ \\
\hline KSU & $8.73(3.28 I)$ & & $6.48(2.489)$ & \\
\hline IAU & $7.32(3.365)$ & & $6.76(2.538)$ & \\
\hline Other & $8.70(3.028)$ & & $6.65(1.954)$ & \\
\hline No applicable & $7.60(3.53 I)$ & & $6.69(2.34 I)$ & \\
\hline \multicolumn{5}{|l|}{ Board } \\
\hline Saudi & $7.75(3.648)$ & independent $t$-test $=-0.769$ & $6.42(2.503)$ & $t=-1.51 \mid$ \\
\hline Other & $8.13(3.400)$ & & $6.90(2.221)$ & \\
\hline
\end{tabular}

Notes: $* p<0.05, * * p<0.001$.

An ANOVA was used for the general relationships between dental care providers and people with special needs to investigate whether such relationships would make a difference in the providers' preparedness to deal with patients with special needs. The result was statistically significant, so relationships with people who had special needs affected the providers' preparedness to treat such individuals $(f=2.915, p=0.017)$.

Regarding the providers' experience treating patients with special needs, we conducted a $t$-test to whether such experience would affect their preparedness to treat these patients. The result was statistically significant: The dental care providers perceived themselves as being more prepared to treat such patients when they had experience treating them $(t=-2.520, p=0.012)$.

The participants with relatively low scores in perceived preparedness were more concerned about their level of training than about the patients' disability, level of dental disease, or behavior; the time required; or the impact on other patients $(f=4.912, p<0.001)$. 
Table 3 Bivariate analysis of the preparedness and willingness and study factors (part 2)

\begin{tabular}{|c|c|c|c|c|}
\hline \multirow[t]{2}{*}{ Variables } & \multicolumn{2}{|c|}{ Preparedness } & \multicolumn{2}{|l|}{ Willingness } \\
\hline & Mean (SD) & Test & Mean (SD) & Test \\
\hline \multicolumn{5}{|c|}{$\begin{array}{l}\text { Relationship to person with developmen- } \\
\text { tal disability }\end{array}$} \\
\hline Friend & $9.64(4.154)$ & $f=2.915^{*}$ & $7.09(1.868)$ & $f=\mid .031$ \\
\hline Neighbor & II $(1.633)^{*}$ & & $5.43(2.299)$ & \\
\hline Relative & $7.35(3.648)$ & & $6.44(2.638)$ & \\
\hline Immediate family member & $6.44(3.6 \mid 4)^{*}$ & & $7.19(2.509)$ & \\
\hline Other & $9.67(3.786)$ & & $5.33(2.517)$ & \\
\hline Not applicable & $8.12(3.312)$ & & $6.81(2.224)$ & \\
\hline \multicolumn{5}{|c|}{$\begin{array}{l}\text { Have you ever treated a person with } \\
\text { a developable disability? }\end{array}$} \\
\hline Yes & $8.71(3.638)$ & independent $t$-test $=-2.520 *$ & $7(2.498)$ & $t=-1.577$ \\
\hline No & $7.53(3.377)$ & & $6.50(2.266)$ & \\
\hline \multicolumn{5}{|c|}{$\begin{array}{l}\text { Primary concern in providing dental } \\
\text { treatments to individuals with develop- } \\
\text { mental disabilities }\end{array}$} \\
\hline Level of disability & $9(3.600)^{* *}$ & $f=3.649 * *$ & $7.22(2.33 \mathrm{I})^{*}$ & $f=3.557^{* *}$ \\
\hline Level of dental disease & $8.91(3.204)^{*}$ & & $6.91(1.905)$ & \\
\hline Patient behaviour & $7.83(3.290)$ & & $6.47(2.265)^{*}$ & \\
\hline My level of training & $6.21(3.388)^{* *}$ & & $5.77(2.091)^{* *}$ & \\
\hline It is time consuming & $9(1.4 \mid 4)$ & & $8(1.4 \mid 4)$ & \\
\hline Impact on other patients & $10.50(3.536)$ & & $6(5.657)$ & \\
\hline Other concern & $7(4.243)$ & & $8.50(4.950)$ & \\
\hline No concerns & $9.46(3.282)^{*}$ & & $8.69(2.658)^{* *}$ & \\
\hline
\end{tabular}

Notes: $* p<0.05, * * p<0.001$.

Abbreviations: KAU, King Abdulaziz University, Faculty of dentistry; KSU, King Saud University, Faculty of dentistry; IAU, Imam Abdulrahaman bin Faisal University, Faculty of dentistry.

Furthermore, the following did not significantly affect the providers' perceived preparedness: their age $(f=0.789$, $p=0.534)$, their job title $(f=1.261, p=0.220)$, their nationality ( $t=0.141, p=0.888$ ), and the agency that provided their board licensing $(t=0.769, p=0.443)$.

We then used a $t$-test to determine that gender $(t=2.822$, $p=0.005$ ) had a statistically significant effect on the providers' willingness to treat patients with special needs (Figure 3). The willingness scores were higher for male participants than for female ones.

The participants with relatively low perceived willingness were more concerned about their level of training than about the patients' disability, level of dental disease, or behavior; the time required; or the impact on other patients $(f=3.557, p=0.001)$.

None of the other variables were significant with regard to the providers' willingness scores: their age $(f=0.970, p=0.134)$, their nationality $(t=0.305, p=0.305)$, the agency that provided their board licensing $(t=-1.511, p=0.132)$, the university where they work or study $(f=1.053, p=0.954)$, their job title
( $f=0.263, p=0.954)$, their college $(f=0.115, p=0.951)$, their general experience with individuals who have developmental disabilities $(t=0.445, p=0.657)$, the relationship between the providers and people with developmental disabilities $(f=1.031$, $p=0.444$ ), and the providers' experience treating patients with developmental disabilities $(t=-1.577, p=0.116)$.

In addition, Tables 4 and 5 shows the multivariable regression analysis for each outcome separately, ie, the preparedness and the willingness. Where in the preparedness model, the gender and the experience were no longer significant when added to the model. While in the willingness model, both variables stayed significant in the model. However, although both models are significant, adjusted-R squared are very low in both models (Model [Preparedness]: $f=3.18, \quad p, 0.000, \quad$ Adjusted $-r^{2}=0.1650$ ), and (Model [Willingness]: $f=4.03, p=0.002$, Adjusted $-r^{2}=0.0943$ ).

\section{Discussion}

The study's results indicate that there are significant differences in the preparedness and willingness scores of 


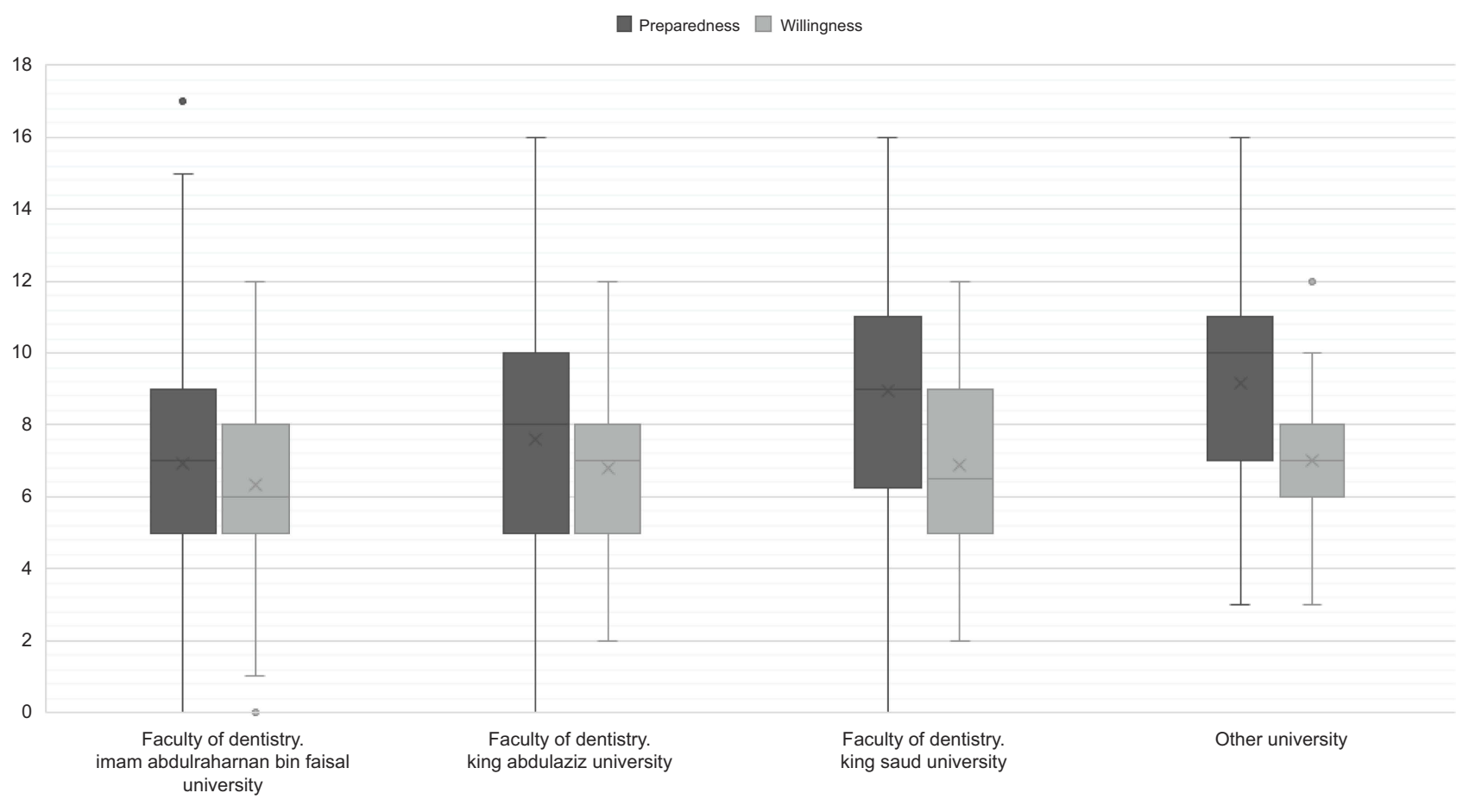

Figure I Differences in the preparedness and willingness scores between participants working or studying at the universities in the study.

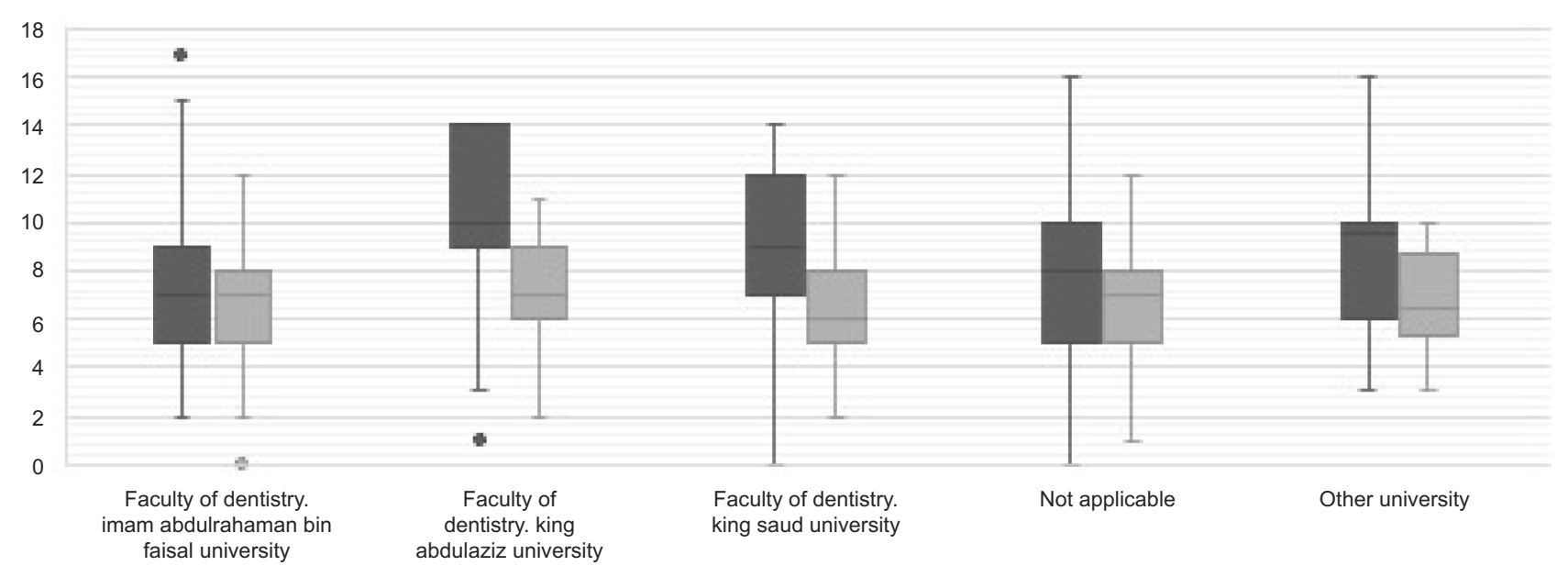

Figure 2 Differences in the preparedness and willingness scores across alumni from different universities in the study.

dental care providers from IAU, KSU, and KAU with regard to treating patients with special needs. Some factors impact the perceptions of these providers with regard to treating such patients. These factors obviously affect the quality of the resulting treatment and the access that individuals with special needs have to dental care.

The providers who were currently affiliated with KSU were better prepared than those from other universities to treat patients with special needs, but they did not show enough willingness to deal with those patients. This may indicate that the training program at KSU best prepares dental care providers to deal with patients who have special needs. However, the participants who graduated from KAU were more preparedness than those who graduated from other universities.

In this study, age did not significantly affect the dental care providers' preparedness or willingness to treat 
Preparedness $\square$ Willingness

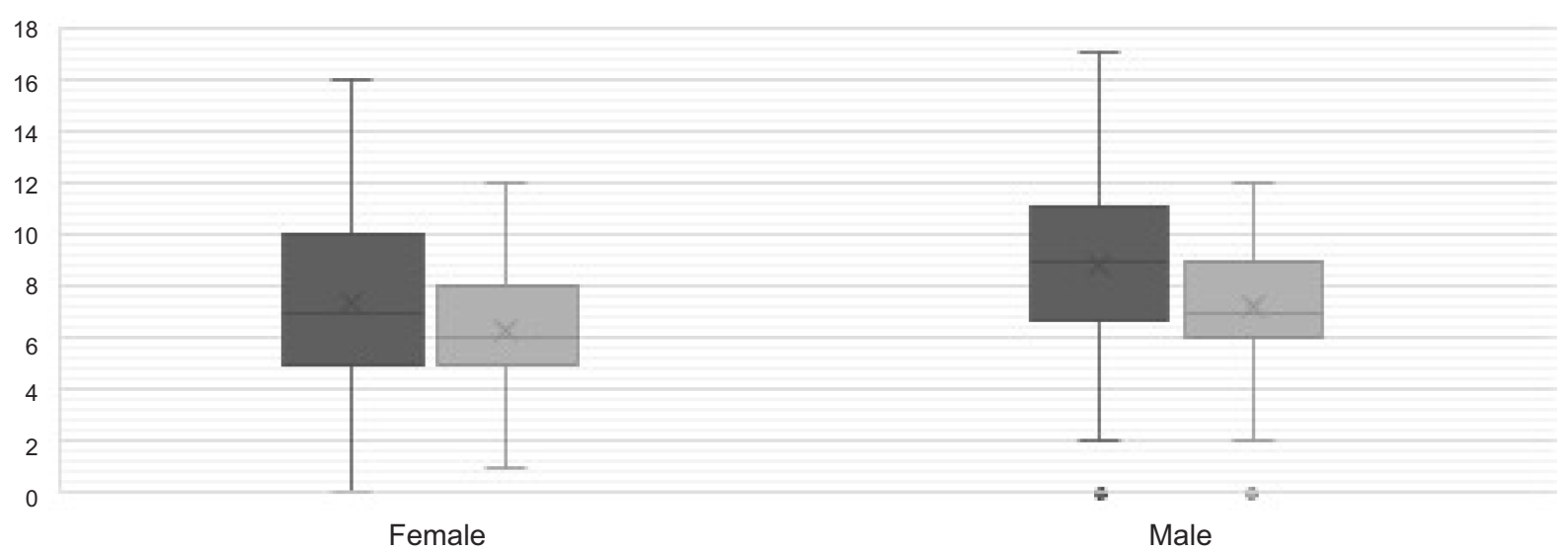

Figure 3 Differences in the preparedness and willingness scores between males and females.

Table 4 Multivariable regression - outcome: Preparedness $f(2 \mathrm{I}, 2 \mathrm{I} \mathrm{I})=3.18 * * *$, R-squared=0.2406, adjusted R-squared=0.1650

\begin{tabular}{|c|c|c|c|}
\hline & Coefficient & $\boldsymbol{t}$ & $95 \% \mathrm{Cl}$ \\
\hline \multicolumn{4}{|l|}{ Gender } \\
\hline Male & Ref & -1.74 & $-1.812769,0.110718$ \\
\hline Female & -0.8510254 & & \\
\hline \multicolumn{4}{|l|}{ University } \\
\hline KAU & Ref & $2.65 * *$ & $0.5450362,3.72 \mid 264$ \\
\hline KSU & 2.13315 & 0.98 & $-0.7|44| I, 2.1 \mid 3945$ \\
\hline IAU & 0.6997671 & $2.15^{*}$ & $0.1564098,3.52804$ \\
\hline Other & 1.842225 & & \\
\hline \multicolumn{4}{|l|}{ Graduation school } \\
\hline KAU & Ref & $-2.97 *$ & $-6.156865,-1.245642$ \\
\hline KSU & -3.701254 & $-3.0 I^{*}$ & $-6.06859,-1.269637$ \\
\hline IAU & -3.669113 & $-2.25^{*}$ & $-5.705153,-0.3819583$ \\
\hline Other & -3.043555 & $-3.23 * *$ & $-5.275804,-1.273348$ \\
\hline NA & -3.274576 & & \\
\hline \multicolumn{4}{|c|}{ Relationship to a person with a developmental disability } \\
\hline Friends & Ref & 0.65 & $-2.128014,4.202777$ \\
\hline Neighbor & 1.037382 & -1.91 & $-4.1736 \mid, 0.0636285$ \\
\hline Relative & -2.054991 & $-2.35^{*}$ & $-5.638476,-0.4953019$ \\
\hline Immediate family member & -3.066889 & -0.12 & $-4.4978 I 7,3.96774 \mid$ \\
\hline Other relations & -0.265038 & -0.60 & $-3.899303,2.077773$ \\
\hline NA & -0.910765 & & \\
\hline \multicolumn{4}{|c|}{ Have you ever treated a person with a developmental disability } \\
\hline No & Ref & 0.39 & $-1.998177,2.977101$ \\
\hline Yes & 0.4894622 & & \\
\hline \multicolumn{4}{|c|}{ What is your primary concern } \\
\hline Level of disability & Ref & -0.34 & $-1.861875,1.31624$ \\
\hline Level of dental disease & -0.2728176 & -1.76 & $-2.146629,0.1186216$ \\
\hline Patient behavior & -1.014004 & $-3.11^{*}$ & $-3.260228,-0.7321323$ \\
\hline My level of training & -1.99618 & 0.06 & $-4.736958,5.047803$ \\
\hline
\end{tabular}

(Continued) 
Table 4 (Continued).

\begin{tabular}{|l|l|l|l|}
\hline & Coefficient & t & 95\% CI \\
\hline It is time consuming & 0.1554224 & 0.57 & $-3.285232,5.951557$ \\
Impact on other patients & 1.333163 & 1.07 & $-0.9080388,3.080126$ \\
No concern & 1.086044 & -0.65 & $-6.205077,3.116964$ \\
Other concern & -1.544056 & & \\
\hline
\end{tabular}

Notes: $* p<0.05, * * p<0.001, * * p<0.0001$.

Table 5 Multivariable regression - outcome: Willingness $f(21$, $2 \mathrm{II})=4.03 * *$, R-squared $=0.1254$, adjusted R-squared $=0.0943$

\begin{tabular}{|c|c|c|c|}
\hline & Coefficient & $\boldsymbol{t}$ & $95 \% \mathrm{Cl}$ \\
\hline \multicolumn{4}{|l|}{ Gender } \\
\hline Male & Ref & $-2.60 *$ & $\begin{array}{l}-1.394562 \\
-0.1907495\end{array}$ \\
\hline Female & -0.792656 & & \\
\hline \multicolumn{4}{|l|}{ Primary concern } \\
\hline Level of disability & Ref & -0.55 & $\begin{array}{l}-1.400858 \\
0.7930873\end{array}$ \\
\hline Level of dental disease & $-0.303885 I$ & -1.97 & $\begin{array}{l}-1.53292 \\
-0.000265\end{array}$ \\
\hline Patient behavior & -0.7665923 & $-3.0 I^{*}$ & $\begin{array}{l}-2.164713 \\
-0.4514696\end{array}$ \\
\hline My level of training & $-1.30809 \mid$ & 0.21 & $\begin{array}{l}-2.863052 \\
3.533 \mid 49\end{array}$ \\
\hline It is time consuming & 0.3350485 & -0.79 & $\begin{array}{l}-4.448909 \\
1.911662\end{array}$ \\
\hline Impact on other patients & -1.268624 & $2.19 *$ & $\begin{array}{l}0.1524 \mid 88 \\
2.87787\end{array}$ \\
\hline No concern & 1.515144 & 1.01 & $\begin{array}{l}-1.563179 \\
4.818587\end{array}$ \\
\hline Other concern & 1.627704 & & \\
\hline
\end{tabular}

Notes: $*_{p}<0.05, * *_{p}<0.001$.

patients with special needs; however, the investigators in another study found that age significantly affected the providers' perceptions; in particular, younger dental care providers had less experience and poorly evaluated the quality of their education. ${ }^{8}$

In this study, the male participants, as compared to the female participants, reported being more prepared and more willing to treat patients with special needs. This is contrary to the findings of a study that was conducted in Riyadh, Saudi Arabia, where it was found that the female dental students' willingness to treat patients with special needs was greater than that of the male students. ${ }^{16}$ Another study, which examined dentists' willingness to treat children with special needs in Nigeria, found that there was no significant difference between males and females. ${ }^{17}$
There is more available evidence on gender as a factor influencing healthcare professionals' attitudes towards treating patients with special needs. ${ }^{18}$ However, further research is needed to investigate the influence of gender, specifically on dentists' willingness to treat patients with special needs.

In addition, this study's results indicate that dental care providers who have experience treating patients with special needs (or even just interacting with them in daily life) are more prepared than other providers to treat those individuals. Similarly, researchers in a previous study indicated that, when dental care providers spend more time with patients who have special needs, those providers become better prepared and better understand these patients' behaviors. ${ }^{14}$

This study's participants expressed the most concern about their level of training and how that influenced their preparedness and willingness to treat patients with special needs. Researchers previously reported that one of the barriers to dental care providers treating patients with special needs was a concern regarding their own level of training. ${ }^{19}$ On the other hand, our results differed from those of other researchers, who reported that patients' behavior was the concern that had the greatest effect on providers' preparedness and willingness. $^{14,20}$

The study's results also indicate that dental care providers who feel prepared to treat patients with special needs are not always willing to do so. These results also reveal that experience plays a major role in preparing dentists to treat patients who have special needs. It is noteworthy that education and experience are important in ensuring that dentists are prepared to handle such patients. A lack of either factor can adversely impact dentists' preparedness to handle patients with various kinds of disabilities.

We conducted this study to identify differences among dental care providers from IAU, KAU, KSU, and other 
institutions. This study's findings provide insights into the best ways to improve dental care providers' perceived preparedness to treat patients with special needs.

Several limitations have affected the outcomes of this study and should be addressed in future work. First, it was difficult to ascertain the accuracy of the information that the participants provided through the online questionnaire. Second, not all Saudi Universities were included in the study, thus the study participants do not represent all dental care providers in Saudi Arabia, so generalizability cannot be assumed. In addition, the results may be biased because we are from IAU, which is where most of the responses were from.

\section{Conclusion}

To our knowledge, this is the first study to measure Saudi Arabian dental care providers' perceived preparedness and willingness to treat patients with special needs. Dental care providers and students from KSU perceived themselves as being more prepared than did those from other universities; however, alumni of KAU perceived themselves as being more prepared relative to alumni from other universities. Furthermore, the providers who had experience treating patients with special needs were more prepared to treat these individuals. In addition, the male participants, as compared to the female participants, reported being more prepared and more willing to treat patients with special needs.

The findings of this study provide insights into how best to improve dental care providers' perceived preparedness to treat patients with special needs. These findings should be seen as an initial step toward improving training and education for dental care providers in Saudi Arabia.

\section{Acknowledgments}

We would like to thank Dr Jehan Alhomaid, the vice dean of students affairs in the College of Dentistry, Imam Abdulrahman bin Faisal University, for her valuable input in the construction of this study. We would also like to thank $\mathrm{Mr}$ Amjad Saadah for his valuable input in reviewing the manuscript. We would like to emphasize that there is no conflict of interest or funding relevant to this study.

\section{Disclosure}

The authors report no conflicts of interest in this work.

\section{References}

1. Ackerman MB. Specialist envy: is special care dentistry a dental specialty or a dental special interest group? Spec Care Dentist. 2016;36(1):3-6. doi:10.1111/scd.12155

2. Steinberg BJ. Issues and challenges in special care dentistry. $J$ Dent Educ. 2005;69(3):323-324.

3. Hon S. Dentistry for individuals with special needs in Saudi Arabia: a commentary. J Disability Oral Health. 1957;2010:60.

4. Heima M, Heaton LJ, Ng HH, Roccoforte EC. Dental fear among transgender individuals a cross sectional survey. Spec Care Dentist. 2017;37(5):212-222. doi:10.1111/scd.12245

5. Mustafa M, Asiri FYI, AlGhannam S, AlQarni IAM, AlAteeg MA, Anil S. Extent of awareness regarding oral health and dental treatment needs among individuals with hearing and speech impairments in Saudi Arabia. J Int Soc Prevent Communit Dent. 2018. doi:10.4103/jispcd.JISPCD 19417

6. Block MJ, Walken JW. Effect of an extramural program on student attitudes toward dental care for the mentally retarded. J Dent Educ. 1980;44(3):158-161.

7. Grantham EV, Block MJ. Effect of extramural experiences on dental students' attitudes. J Dent Educ. 1983;47(10):681-684.

8. Dao LP, Zwetchkenbaum S, Inglehart MR. General dentists and special needs patients: does dental education matter? $J$ Dent Educ. 2005;69(10):1107-1115.

9. Moore PA, Boynes SG, Cuddy MA, Giovannitti JA, Zovko J. Educational experiences and preparedness in dental anesthesia: five-year outcome assessment and conclusions. J Dent Educ. 2009;73(12):1379-1386.

10. Holder M, Waldman HB, Hood H. Preparing health professionals to provide care to individuals with disabilities. Int J Oral Sci. 2009;1(2):66. doi:10.4248/ijos. 09022

11. Gallagher J, Fiske J. Special care dentistry: a professional challenge. Br Dent J. 2007;202(10):619. doi:10.1038/bdj.2007.426

12. Organization WH. Oral health. 2012. Available from:

13. Alumran A, Almulhim L, Almolhim B, Bakodah S, Aldossary H, Alakrawi Z. Preparedness and willingness of dental care providers to treat patients with special needs. Clin Cosmet Investig Dent. 2018;10 (1):231-236. doi:10.2147/CCIDE.S178114

14. Alkahtani ZM, Stark PC, Loo CY, Wright WG, Morgan JP. Saudi and US dental student attitudes toward treating individuals with developmental disabilities. J Dent Educ. 2014;78(8):1145-1153.

15. IBM SPSS Statistics for Windows [Computer Program]. Armonk, NY: IBM Corp; 2010.

16. Pani S, Al Shalan A, Al Saigh H, Shaheen R, Radwan V. Saudi dental students' perception of their education in Special Care Dentistry and its effect on their confidence to render care. J Disability Oral Health. 2012;13(1):19-25.

17. Oredugba FA, Sanu OO. Knowledge and behavior of Nigerian dentists concerning the treatment of children with special needs. $B M C$ Oral Health. 2006;6(1):9. doi:10.1186/1472-6831-6-9

18. Satchidanand N, Gunukula SK, Lam WY, et al. Attitudes of healthcare students and professionals toward patients with physical disability: A systematic review. Am J Phys Med Rehabil. 2012;91(6):533-545. doi:10.1097/PHM.0b013e3182555ea4

19. Tsai W-C, Kung P-T, Chiang -H-H, Chang W-C. Changes and factors associated with dentists' willingness to treat patients with severe disabilities. Health Policy. 2007;83(2):363-374. doi:10.1016/j. healthpol.2007.02.011

20. Casamassimo PS, Seale NS, Ruehs K. General dentists “ perceptions of educational and treatment issues affecting access to care for children with special health care needs. J Dent Educ. 2004;68 (1):23-28. 


\section{Publish your work in this journal}

The Journal of Multidisciplinary Healthcare is an international, peerreviewed open-access journal that aims to represent and publish research in healthcare areas delivered by practitioners of different disciplines. This includes studies and reviews conducted by multidisciplinary teams as well as research which evaluates the results or conduct of such teams or healthcare processes in general. The journal covers a very wide range of areas and welcomes submissions from practitioners at all levels, from all over the world. The manuscript management system is completely online and includes a very quick and fair peer-review system. Visit http://www.dovepress.com/testimonials. php to read real quotes from published authors. 